\title{
ESCARABEOS INÉDITOS DE LA PROVINCIA DE SEVILLA
}

\author{
UNPUBLISHED SCARABS FROM THE SEVILLA PROVINCE
}

\author{
por \\ MARÍA ANTONIA GARCÍA MARTÍNEZ*
}

\section{ESCARABEO (fig. I)}

El escarabeo es de cornalina roja y está montado en caja de oro. Mide 1,5 $\mathrm{cm}$. de longitud por 1,05 $\mathrm{cm}$. de anchura. Procede de zona indeterminada de la provincia de Sevilla, donde se conserva en colección particular.

La caja de oro es abierta en ambas caras del escarabeo. El esquema dorsal de éste es de tipo IV, con tórax y élitros bien marcados, de acuerdo con la clasificación de Newberry (1906: 69; 1907 XIX), adoptada por Vercoutter (1945: 49 ss., 71 ss.) y por Padró (1980: 55). Tiene las patas lateralmente indicadas con incisión profunda y cuenta con perforación longitudinal.

En su base, enmarcada por línea sencilla irregular, aparecen trabajados con muy buena técnica los dioses Maat y Horo orientados hacia la derecha. Maat, sedente, tiene la pluma $m 3^{`} t$ que la identifica, repetida sobre sus rodillas y en la cabeza. Tras ella el halcón Horo con las alas desplegadas adelanta una garra en señal de protección. Ante ambos, el signo jeroglífico dí ofrece la lectura del conjunto "Dado por Maat y Horo."

Las representaciones del dios Horo haciendo este gesto de protección tras diferentes deidades son bien conocidas en escarabeos hallados en Egipto (Petrie 1917: XL, 19.25, XLV, 12; Newberry 1907: III), Cartago (Vercoutter 1945: $119 \mathrm{n}^{\circ} 103,153 \mathrm{n}^{\circ} 240,161 \mathrm{n}^{\circ} 268$ ) y la Península Ibérica (Boardman 1984: V, 25). En un escarabeo procedente de Mas Mussols, Tarragona, el halcón protege a una esfinge que representa al faraón (Padró 1983: 92-94, L, LI, 10.01). En ocasiones Horo acompaña a

(*) Agradezco al Profesor García Dieguez sus amables indicaciones para la localización de varias piezas conservadas en colecciones privadas. Omitiendo aquí mi opinión personal respecto a la posesión privada de piezas arqueológicas, así como mis sugerencias sobre las posibles soluciones legales para que el hallazgo de las mismas fuese de dominio público y su localización y estudio viables -por reconocer que ninguna de las que puedo concebir garantizaría su total efectividad- he de agradecer sin embargo la amabilidad con que se me ha facilitado el acceso al estudio de estos anillos. La reflexión privada y oficial sobre el valor histórico de estos documentos, insustituible por cualquier otro de tipo material que pueda estimarse para las mismas, razonablemente debiera llevarnos a actitudes en las que el altruismo fuese componente fundamental. 
un cartucho real (Petrie 1917: XLV, 4; Newberry 1907: IX, 36326). En uno de estos ejemplares con el praenomen de Rameses II, Maat y Horo aparecen en la misma actitud que en esta pieza en estudio (Petrie 1917: XL, 28).

En base a sus paralelos se trata de un escarabeo manufacturado en Egipto, fechable entre los siglos VII y VI a.C., teniendo en cuenta el límite cronológico que generalmente ha venido siendo aceptado para la colonización fenicia peninsular. Si bien, dada la relativa frecuencia de hallazgos arqueológicos peninsulares que podrían documentar un desplazamiento de dicha colonización hacia las fechas anteriores transmitidas por las fuentes clásicas, en base a los paralelos de este escarabeo, su datación puede ser también anterior, ya que se trata de un modelo tradicionalmente repetido en Egipto.

\section{ESCARABEO (fig. II)}

Esta pieza fue entregada en 1983 al Museo Arqueológico Provincial de Sevilla, donde actualmente se conserva, por D. Pedro Hurtado, quien halló la misma casualmente en Searo, término de Utrera, Sevilla.

Es de pasta verde sin restos de barniz exterior alguno y mide $1,35 \mathrm{~cm}$. de longitud, $1 \mathrm{~cm}$. de anchura y $0,8 \mathrm{~cm}$. de grosor.

Su esquema dorsal es de tipo IVb, con tórax y élitros bien definidos mediante doble línea. Las patas del insecto fueron correctamente grabadas con incisión profunda. El clipeo fue resaltado mediante cuatro óvalos estrechos convergentes en uno de sus extremos. Cuenta con perforación longitudinal para su suspensión o engarce y su estado de conservación es bueno.

Su base, decorada con línea sencilla, ofrece una deidad muy esquemática y deficientemente definida, coronada con el disco solar y sentada hacia la izquierda con las piernas flexionadas junto al cuerpo, sobre las que se aprecia el extremo superior de un signo anj muy simplificado.

El esquematismo del trazado impide identificaciones seguras, si bien la figura parece representar al signo jeroglífico C2 de Gardiner (1969: 448, C2, 449), consistente en un personaje hieracocéfalo coronado con el disco solar y exhibiendo un anj sobre sus piernas, dispuestas de igual modo que la figura representada en el escarabeo en estudio.

Los signos que evocan a distintas deidades egipcias en cuclillas fueron muy populares a lo largo de toda la historia egipcia y aparecen representados en los escarabeos de cualquier época (Petrie 1925: $\mathrm{XV}, 1034,1036,1039,1043$, entre otros), a menudo acompañando a los nombres de diversos reyes (Petrie 1917: LIV nn. 25L9, 25L10; LV nn. 24-26). Conocemos el mismo tipo de imagen en escarabeos procedentes de Cartago (Vercoutter 1945: 107-109, nn. 49-60). Uno de ellos ofrece una representación de Re hieracocéfalo que constituye el paralelo más cercano para la deidad del ejemplar del Museo de Sevilla, aunque aquél fue grabado con técnica muy superior a la de éste (Vercoutter 1945: $109 \mathbf{n}^{\circ}$ 60). Contamos también con paralelos hallados en Cerdeña (Scandone 1975: VII, VIII, nn. D2, D3) y en la Península Ibérica (Padró 1985: 129-131, CXLIV, CSLVI, nn. 31.01-31.03).

Éste es un escarabeo manufacturado en Egipto, datable entre los siglos VII y VI a.C. en base a los paralelos que fueron distribuídos por los colonizadores del Mediterráneo, cronología que al igual que la del escarabeo precedente, podría ser anterior si también lo fuese la correspondiente a la de la debatida fundación fenicia de Cádiz. 


\section{ESCARABEO (fig. III)}

Este escarabeo procede de zona indeterminada de la provincia de Sevilla. Es de pasta blanca y está montado en caja de plata abierta por ambas caras. Mide $1,8 \mathrm{~cm}$. de longitud, $1,1 \mathrm{~cm}$. de anchura y 0,8 $\mathrm{cm}$. de grosor.

La pieza fue trabajada con técnica aceptable pero su estado de conservación es deficiente, careciendo de algunos fragmentos que no impiden sin embargo reconocer su grabado.

El dorso es de tipo IVb, con tórax y élitros bien definidos mediante doble línea, en parte desdibujada. Las patas del escarabeo y su posible perforación longitudinal quedan ocultas por la montura. Su base ofrece tres registros. El superior de ellos muestra a dos aves rapaces distintas enfrentadas, muy probablemente halcón y buitre. En el registro intermedio aparece una vaca sentada hacia la derecha seguida del signo jeroglífico $h 3$. El campo inferior, afectado por una de las roturas, contiene un signo $n b$ y escasos restos de lo que podría ser un cetro $w 3 s$.

La distribución de figuras en tres registros es bien conocida en los escarabeos egipcios. Elementos constantes para muchos de ellos son el signo $n b$ inferior, el signo de protección $h 3$, "estar detrás", "vigilar", central asociado a distintas deidades y una o dos divinidades en el campo superior (Vercoutter 1945: $156 n^{\circ} 247 ; 158 n^{\circ} 251 ; 160 n^{\circ} 264 ; 186 n n .410,411$ ). Ninguno de estos paralelos ofrece sin embargo una representación igual a la del escarabeo en estudio, presidida por los dioses Horo y Nejbet, con la vaca, símbolo de la diosa Hathor, en el centro, siendo el más próximo un ejemplar procedente de Cartago con un buitre en su campo superior, un halcón junto al signo $h 3$ central y un $n b$ inferior.

Este es un escarabeo manufacturado en Egipto, fechable entre los siglos VII y VI que admitiría una datación anterior según se ha comentado en relación con los ejemplares anteriores.

\section{ESCARABEO (fig. IV)}

La persona que halló y conserva esta pieza indica que procede de la zona de Los Alcores, sin especificar otros datos acerca de la exacta localización de su contexto arqueológico. Es de pasta roja con núcleo blanco que aparece en las incisiones de su inscripción. No conserva restos de vidriado alguno. Mide $1,6 \mathrm{~cm}$. de longitud, $1,3 \mathrm{~cm}$. de anchura y $0,7 \mathrm{~cm}$. de grosor.

Su esquema dorsal es de tipo IV, con tórax y élitros marcados. Las patas están indicadas con poca precisión y superficialmente. Cuenta con perforación longitudinal.

El escarabeo se conserva en buen estado y fue trabajado con técnica aceptable. Su base está enmarcada mediante motivo pseudosogueado y dividida en dos campos. En el superior, dos plumas $m 3^{\circ} t$ encuadran un cartucho real con el praenomen de Micerino, $M n-K 3 w-R^{\prime}$. En el registro inferior aparece un escarabeo flanqueado por dos signos $~ n h$, descansando sobre un signo $n b$. Estos símbolos muy a menudo acompañan a distintos nombres reales sin necesidad de formar una frase concreta, invocando la vida y la renovación espiritual, o bien integrados en la expresión: "El Señor de la Vida y la Existencia".

Los escarabeos egipcios datables en fechas próximas al reinado de Micerino (IV dinastía, c. 2613-2498), ofrecen la forma correcta de su praenomen, $M n-K 3 w-R$, con el plural $k 3 w$, es decir dos brazos extendidos hacia arriba tres veces repetidos (Petrie 1917: IX, 3). Sin embargo muchas de las copias que, evocando al mismo rey convertido en dios de acuerdo con las concepciones egipcias, fueron puestas en circulación en Época Saíta (664-525 a.C.), repiten su praenomen deformado con el signo $k 3$ en singular. Así aparece en varios paralelos procedentes de Cartago (Vercoutter 1945: 97, nn. 12-15; 98, nn. 16-18; 177, nn. 372-375, entre otros). 
Este escarabeo, fechable en base a sus paralelos entre los siglos VII y VI, es hasta ahora el único ejemplar con el praenomen de Micerino procedente de la Península Ibérica.

\section{ESCARABEO (fig. V)}

Esta pieza es de piedra opaca azul verdosa y mide $1,35 \mathrm{~cm}$. de longitud por $1,05 \mathrm{~cm}$. de anchura. Se conserva en una colección particular de Sevilla, desconociéndose los datos sobre su procedencia de la misma provincia.

$\mathrm{Su}$ esquema dorsal es de tipo IVb, con tórax marcado mediante doble línea y élitros bien definidos. La indicación lateral de las patas del insecto está hecha de forma tosca y poco precisa. Cuenta con perforación longitudinal. Su base está muy desgastada y las figuras en ella inscritas muy desdibujadas. Una de éstas podría representar a un personaje de facciones negroides adelantando su pierna derecha y empuñando una lanza con la mano izquierda, vistiendo un largo manto que parece formar ángulo recto al caer al suelo. Ante él, un individuo con barba, de reducida estatura y tocado puntiagudo, quizás Bes, aparece orientado hacia la derecha. Sobre el segundo hay unos pequeños motivos inidentificables, uno de ellos tal vez un disco solar.

Este es un escarabeo púnico fechable entre los siglos IV y III. Bes fue a menudo representado en los escarabeos púnicos de Ibiza (Fernández y Padró 1928: 84-86), pero no conocemos paralelo alguno en que aparezca emparejado con un personaje como el del escarabeo en estudio. Este podría quizás ser identificado con Heracles, si su manto correspondiese al de piel felina característico de este dios. Pero el desgaste de esta figura desdibujada impide aproximaciones fidedignas que la identifiquen.

\section{ESC̣ARABEO (fig. VI)}

Es de piedra negra y mide $2,1 \mathrm{~cm}$. de longitud, por $1,4 \mathrm{~cm}$. de anchura y $1,2 \mathrm{~cm}$. de grosor. Procede de lugar indeterminado de la provincia de Sevilla.

Su dorso es del tipo IIIb, añadido por J. Padró (1980: 55) a la tradicional tipología de Newberry (1906: 69 ss., 1907: XIX) con élitros definidos -en este caso sólo levemente indicados mediante una pequeña línea en un extremo de los mismos- y sin tórax. También las patas del insecto fueron levemente insinuadas mediante una ligera línea superficial. Cuenta con perforación longitudinal.

El grabado de su base es esquemático y trabajado con técnica muy pobre. Un león sobre sus patas traseras aparece atacando a un cuadrúpedo, al que sujeta con las patas delanteras.

Las escenas en que un león o un pájaro atacan a distintos tipos de animales parecen tener origen asiático (Padró 1983: 21). Este tipo de representación es conocida en los escarabeos de manufactura egipcia que circularon tanto en su lugar de origen (Newberry 1907: 115, VII, $n^{\circ} 36456$; Gardner 1888: XVIII, 7), como en el Mediterráneo occidental (Vercoutter 1945: 159 nº 258; Padró 1983: 19-22, XXXIII $\mathrm{n}^{\circ}$ 04.01). Fue después repetida en piezas de fabricación púnica, cuya distribución conocemos en Cartago (Vercoutter 1945: 232, 233, nn. 623-625; 253 n 713), en Ibiza (Fernández y Padró 1982: 86-93, nn. 26-30), Cerdeña (Walters 1926: 50, VII n ${ }^{\circ} 418$ ) y Etruria (Walters 1926: 92, XIII $n^{\circ} 755$ ). El escarabeo en estudio es de manufactura púnica y fechable, en base a sus paralelos, entre los siglos IV y III a.C. 


\section{ESCARABEO (fig. VII)}

Ésta es una pieza de amatista azul claro con $1,8 \mathrm{~cm}$. de longitud, $1,6 \mathrm{~cm}$. de anchura y $0,8 \mathrm{~cm}$. de grosor. Procede de zona que no ha sido determinada de la provincia de Sevilla.

El esquema dorsal del escarabeo es de tipo IVb, con tórax bien definido y élitros indicados de forma elaborada, longitudinalmente grabados mediante líneas paralelas en toda su superficie. Lateralmente una leve incisión sólo indica, sin llegar a trazar, las patas del insecto. Cuenta con perforación longitudinal.

En su base, mirando hacia la izquierda, aparece el dios Anubis vistiendo atuendo romano, con la pierna izquierda hacia atrás en actitud de caminar. Su brazo izquierdo rodea un caduceo que mantiene junto al cuerpo. Su mano derecha, adelantada, sujeta una corona de laurel y un cetro.

Este ejemplar romano es una pieza realmente excepcional, ya que una vez detenida la fabricación y tráfico de escarabeos pseudoegipcios fechables entre los siglos IV y III a.C., que a su vez suplían la falta de manufactura y comercio de escarabeos egipcios que siguió a la invasión persa de Egipto (525 a.C.), este tipo de amuleto parece haber quedado totalmente fuera de uso, desapareciendo en época romana.

Por el contrario la iconografía egipcia, así como una parte importante de su simbolismo original, subsistió adaptada a la estética romana en el propio Egipto y en el ámbito mediterráneo. En concreto las representaciones del dios Anubis en atuendo romano fueron usuales en el propio Egipto (Michalowski 1968: 428 nn. 684, 686, 689). Fuera de Egipto también han sido halladas imágenes de este dios de estilo romano, dada la vinculación de Anubis a los cultos isíacos tan difundidos en Roma y en sus provincias (García y Bellido 1967). Del yacimiento marroquí de Valentia Banasa procede un bajorrelieve en piedra de un busto del mismo dios, representado también de perfil como aparece en el escarabeo en estudio, en actitud poco convencional, que podría ser de época romana (Thouvenot 1941: 50, VI, fig. 20).

El escarabeo en estudio es más probablemente datable en fecha próxima al dominio romano sobre los ejércitos cartagineses en la Península Ibérica, a finales del siglo III a.C., ya que su presencia en este ámbito podría ser más lógicamente debida a una continuidad del hábito púnico de reproducir los ejemplares egipcios.

\section{BIBLIOGRAFÍA}

FERNÁNDEZ, J. y PADRÓ, J. (1982): Escarabeoos del Museo Arqueológico de Ibiza, en Trabajos del Museo Arqueológico de Ibiza 7.

GARCÍA Y BELLIDO, A. (1967): Les Religions Orientales dans l'Espagne Romaine. Leiden.

GARDINER, A. (1969): Egyptian Grammar being an Introduction to the Study of Hieroglyphs (tercera edición). Londres.

GARDNER, E.A. (1888): Naukratis. Part II. Sixth Memoir of the Egypt Exploration Fund. Londres.

NEWBERRY, P.E. (1906): Egyptian Antiquities. Scarabs. An Introduction to the Study of Egyptian Seals and Signet Rings, Londres.

(1907): Catalogue Général des Antiquités Egyptiennes du Musée du Caire, Nos. 36001-37521. Scarab-shaped Seals. Londres.

PADRÓ, J. (1980): Egyptian-Type Documents from the Mediterranean Littoral of the Iberian Peninsula before the Roman Conquest. I. Introductory Survey. Leiden.

(1983): Egyptian-Type Documents from the Mediterranean Littoral of the Iberian Peninsula before the Roman Conquest. II. Study of the Material. From Western Languedoc to Murcia. Leiden.

- (1985): Egyptian-Type documents from the Mediterranean Littoral of the Iberian Peninsula before the Roman Conquest. III. Study of the Material. Andalusia. Leiden. 
(1987): "La Transcripción Castellana de los Nombres Propios Egipcios", Aula Orientalis 5.

PETRIE, W.M. F. (1917): Scarabs and Cylinders with Names. Londres.

(1917): Scarabs and Cylinders with Names. Londres.

(1925): Buttons and Design Scarabs. Londres.

THOUVENOT, R. (1941): Une Colonie Romaine de Maurétanie Tingitane: Valentia Banasa. París.

VERCOUTTER, J. (1945): Les Objets Egyptiens et Egyptisants du Mobilier Funéraire Carthaginois. París.

WALTERS, R. (1926): Catalogue of the Engraved Gems and Cameos, Greek, Etruscan and Roman in the British Museum. Londres. 

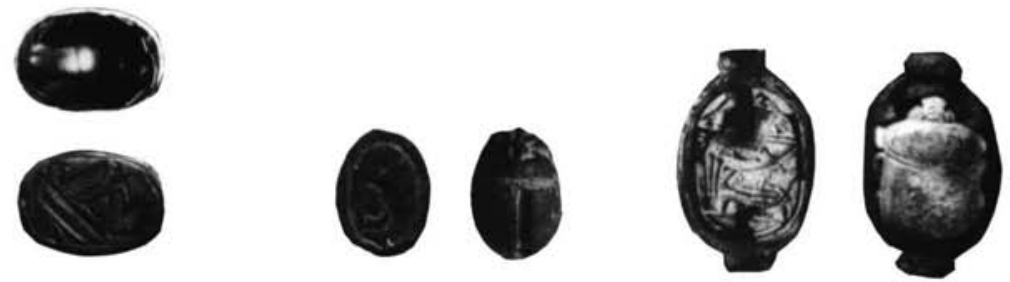

Fig. I

Fig. II

Fig. III
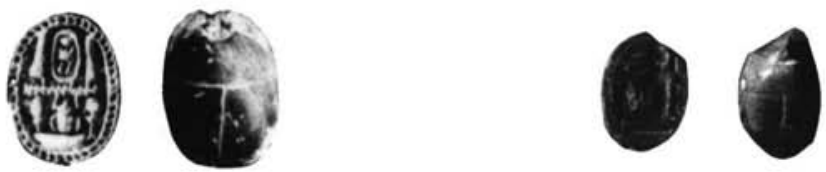

Fig. IV

Fig. V

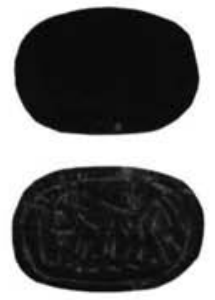

Fig. VI

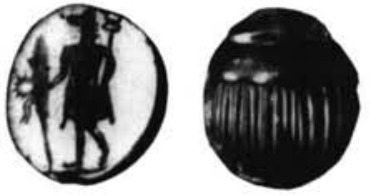

Fig. VII

LÁMINA I (Escala: 1.5/1) 